\title{
Educational Intervention to Foster Best Infection Control Practices
} Among Nursing Staff

\author{
Ujjwala Nitin Gaikwad, ${ }^{1,}{ }^{*}$ Silpi Basak, ${ }^{2}$ Priti Kulkarni, ${ }^{3}$ Suvarna Sande, ${ }^{2}$ Swati Cahavan, ${ }^{2}$ Gargi Mudey, ${ }^{2}$ \\ Nilima S Tankhiwale, ${ }^{2}$ Ramesh P Fule, ${ }^{2}$ and Nitin R Gaikwad ${ }^{4}$ \\ ${ }^{1}$ Department of Microbiology, All India Institute of Medical Sciences, Raipur, Chhattisgarh, India \\ ${ }^{2}$ Department of Microbiology, Jawaharlal Nehru Medical College, Datta Meghe Institute of Medical Sciences, Sawangi (Meghe), Wardha, Maharashtra, India \\ ${ }^{3}$ Samarpan Hospital, Nagpur, Maharashtra, India \\ ${ }^{4}$ Department of Pharmacology, All India Institute of Medical Sciences, Raipur, Chhattisgarh, India \\ Corresponding author: Dr. Ujjwala Nitin Gaikwad, Department of Microbiology, All India Institute of Medical Sciences, Raipur, Chhattisgarh, India. Tel: +91-8518881724, E-mail: \\ ujugaikwad@gmail.com
}

Received 2017 January 11; Revised 2017 January 31; Accepted 2017 January 31.

\begin{abstract}
Background: The continuous education of healthcare workers (HCW) is considered as one of the key components of infection control programs. Since nurses are the frontline healthcare staff; their optimal and periodic training in basic infection control practices is essential.

Objectives: The current study aimed at assessing the pre-existing knowledge and evaluating the effectiveness of one day educational activities to improve the knowledge regarding infection control practices.

Methods: A whole day educational activity comprising didactic lectures and hands-on training on routine infection control practices was conducted for a group of 34 nursing staff. Cognitive gain was assessed using a pre-validated, pre- and posttest questionnaire. The participants' perceptions of the entire educational activity were scored based on a five-point Likert scale.

Results: The average percentage of test score increased significantly from 19.71\% (pretest score: $3.94 \pm 2.3$ ) to 76.69\% (posttest score: $15.33 \pm 2.4)$. The class-average normalized gain was 0.7097 (70.97\%). The mode rating score of the participant's perception increased from 3 (good) to 4 (very good).

Conclusions: Educational intervention had a significant impact on the improvement in the knowledge of nursing staff. Similar periodic interventions should be encouraged to facilitate the learning of HCWs on the best infection control practices.
\end{abstract}

Keywords: Hospital Acquired Infections, Nursing Staff, Educational Intervention, Infection Control

\section{Background}

Hospital acquired infections, also known as healthcare associated infections (HAIs) are among the most common adverse events in hospitals with significant morbidity and mortality rates, and financial losses associated with health care systems. According to the World Health Organization (WHO) estimates, out of every 100 hospitalized patients at any given time, seven in the developed and 10 in the developing countries, acquire at least one healthcare-associated infection (1). The multipronged approach aiming to reduce HAIs in hospitals includes implementing standard precautions, particularly hand hygiene at each level of patient care, ensuring that core components for infection control are in place, improving surveillance of hospital acquired pathogens in hospitals, and finally improving staff education and accountability.

Infection control education is a core component of infection control programs since they were established and they remain a constant feature in the modern healthcare context (2). Healthcare workers (HCWs) should be equipped with the requisite knowledge, skill, and attitude for good infection control practices (3). Education through various means imparts knowledge about the correct practices, and also helps to update the existing knowledge according to the changing scenarios. It is also clear that few of the educational interventions have a measurable prolonged effect (4). A variety of educational strategies are evaluated for their effectiveness as a measure of infection control (5). Some of the most practiced methods are quasiexperimental settings where control and target groups are subjected to both didactic and practical sessions (6), scenario-based simulation training (7), face to face seminars delivered by nurses on an annual basis (8), e-learning followed by questionnaire and focused group discussions 
$(9,10)$, and computer assisted learning (CAL) in infection control education (11).

The role of educational activities such as continuing medical education (CME) to enhance the knowledge and change the attitude is proved in many studies. Davis et al. (12), in their review of 14 studies concluded that "interactive continuing medical education sessions that enhance participant activity and provide the opportunity to practice skills can affect changes in professional practice and on occasions, health care outcomes". In another review, including 69 studies, O'Brien et al. (13) concluded that educational outreach visits alone or combined with other interventions have effects on prescribing drugs that are relatively consistent and small, but potentially important.

All the healthcare personnel are equally responsible to prevent HAIs, but nurses are the most important frontline staff (14). They play a critical role in controlling infection that begins with early detection and surveillance technique (15). Hence, nursing staff should be adequately educated in the basic principles of infection control and should undergo continuous trainings to acquire up-todate knowledge and skills. As a part of ongoing infection control training of HCWs, periodic workshops/CMEs are organized for them. The current study represents the data collected from the evaluation of a one-day workshop conducted on the nursing staff.

\section{Objectives}

The current study aimed at assessing the existing knowledge about the basic infection control practices and evaluating the effectiveness of one-day educational activities on the improvement of the knowledge base.

\section{Methods}

\subsection{Place of the Study}

A tertiary care rural medical college and hospital, India.

The study was conducted as a part of the periodic training program of the hospital nursing staff by the Hospital Infection Control Committee. The study comprised 34 nursing staff as participants. All the participants were initially given the pretest questionnaire comprising 10 questions of two marks each (Table1). The educational intervention comprised of a day-long program consisting of two activities as follows:

Interventional activity No. 1 - This activity comprised of didactic presentations on various themes (topics) of hospital infection control by the senior teaching fraternity of the hospital. The covered topics were Hospital acquired infections, standard precautions, sterilization, disinfection and cleaning, maintaining an operation theatres (OT) discipline, housekeeping practices in the hospital, dealing with an occupational exposure.

Interventional activity No.2 - The activity involved hands-on training by the faculty members about important routine procedures related to infection control such as handwashing, donning and removal of gloves, working with an autoclave, preparing in use dilutions of disinfectants, fumigation and fogging, segregation, and disposal of biomedical wastes. Printed standard operating procedures upon the above procedures were also distributed among the participants.

Following the educational intervention, the participants were subjected to posttest questionnaire. The total maximum score for the test was 20 . Both pretest score and posttest score for each participant were compared with assess the improvement in knowledge regarding the infection control practices. To ascertain the participant's level of perception about the topics covered in the activity, they were subjected to a pre-validated feedback form containing the set of parameters.

\subsection{Statistical Analysis}

The pre- and posttest scores were compared using paired t test and the significance level (P-value) was set to 0.05. The perception levels of the participants were assessed by analyzing a pre-validated feedback form on a fivepoint Likert scale.

\begin{tabular}{|ll}
\hline Table 1. Questionnaire for Pretest -Posttest \\
\hline Item No. & Theme \\
\hline $\mathbf{1 .}$ & Holding time and temperature of autoclave \\
\hline $\mathbf{2}$ & Commonly used disinfectants and their concentrations \\
\hline $\mathbf{3}$ & $\begin{array}{l}\text { Chemicals that can be used as sterilizing agents and their } \\
\text { concentrations }\end{array}$ \\
\hline $\mathbf{4}$ & Universal safety precautions / standard precautions \\
\hline $\mathbf{5}$ & Indications for hand washing \\
\hline $\mathbf{6}$ & Cleaning schedule of operation theatres \\
\hline $\mathbf{7}$ & Chemicals with their quantity used for fumigation of a room \\
$\mathbf{8}$ & Type of biomedical waste that cannot be incinerated \\
\hline $\mathbf{9}$ & The way of disposal of used needles and syringes \\
\hline $\mathbf{1 0}$ & $\begin{array}{l}\text { Management of accidental spillage of blood and body fluids at } \\
\text { the workplace }\end{array}$ \\
\hline
\end{tabular}




\section{Results}

\subsection{Participant's Response Rate}

The response rate of participants was 100\% $(n=34)$ in attempting both pretest and posttest questionnaire as well as the overall feedback $(n=34)$.

\subsection{Cognitive Learning Gain}

The percentage of the posttest score for each question was higher than that of the pretest score (Figure 1). The average test score increased significantly from $19.71 \%$ (average pretest score: $3.94 \pm 2.3$ ) to $76.69 \%$ (average posttest score: $15.33 \pm 2.4)(\mathrm{P}<0.05)$. The absolute learning gain was $56.99 \%$, while relative learning gain was $289.18 \%$. The class-average normalized gain for educational intervention was 0.7097 (70.97\%) (Table 2). The absolute learning gain for each question is shown in Figure 2.

\begin{tabular}{lc}
\hline \multicolumn{2}{l}{ Table 2. Pretest and Posttest Scores and Cognitive Learning Gain ${ }^{\mathrm{a}, \mathrm{b}}$} \\
\hline Score/Gain & Value \\
\hline Pretest score, \% & $3.94 \pm 2.3(19.71)$ \\
\hline Posttest score, \% & $15.33 \pm 2.4(76.69)^{\mathrm{c}}$ \\
\hline Absolute learning gain & 56.99 \\
Relative learning gain & 289.18 \\
\hline Class average normalized ratio & 70.97 \\
\hline
\end{tabular}

${ }^{\mathrm{a}}$ Values are expressed as mean $\pm \mathrm{SD}$ or N. (\%).

${ }^{\mathrm{b}}$ Maximum score of the test $=20$

${ }^{\mathrm{c}} \mathrm{P}<0.05$ using the Student paired t test (pretest vs posttest scores).

\subsection{Participant's Feedback}

Cronbach's alpha, a measure for internal consistency of questionnaire items, was 0.74 . The participants perceived this educational activity as useful. The participants' rating score on a five-point Likert scale ranged 2 to 3 before the intervention and 4 to 5 after the intervention (Table 3.) The mode rating score increased from 3 (good) to 4 (very good) for all the items.

\section{Discussion}

Infection control in health care settings is an important and the sole responsibility of all HCWs. Amongst the various components of infection control programme, education of HCWs on safe and best infection control practices plays a pivotal role. Nurses represent the largest group of workers within the healthcare system than any other HCW. They comprise the first line care providers to the patients, and serve as the heart and hands of the health team (16). Hence, it is mandatory that they practice infection control precautions safely and competently at all time. To ensure this, it is important to keep their knowledge and skills regarding infection control up-to-date. In the existing curriculum of undergraduate medical and nursing disciplines, prevention and control of HAIs is accorded with a very little emphasis (17). Most often, it is restricted to few didactic lectures on important aspects of infection control, aiming at attainment of only theoretical knowledge (16). There is less effort towards empowering them with a skill-based learning to positively affect their attitude while working independently, thus avoiding the adverse consequences. Formal training in infection control is conducted by some hospitals as a short term certificate course. However, this is entirely an optional step and is undertaken by the nursing staff purely on the basis of their own interest or sometimes as a professional obligation to suit the needs of their job description.

Although the extent and quality of infection control education as a part of nursing curriculum is an unresolved issue, it is still an essential constituent of the orientation process in each healthcare facility. Hence, imparting knowledge about the basic infection control practices and regularly updating the same by means of continued medical or nursing education forms the mainstay of infection control program of any hospital.

The current study focused on the in-charge nurses as well as senior staff nurses from each of the clinical departments. Inclusion of senior level nursing staff in the activity aimed at empowering them with the correct principles of infection control, which can be disseminated to the staff working under them. As stated by Cristopher et al. (2), empowering a core group of nurses helps to improve their own knowledge and facilitates their capability to train others as change agents, thereby improving clinical practice to reduce HAIs. A master trainer's course run by some leading hospitals also intends to achieve the same objective (14).

The participants in the current study did not have any kind of formal training in infection control in the past. Therefore, the baseline knowledge was assessed in the current study, using the pretest, probably had its link with whatever was taught to them during graduation/postgraduation or daily routine they were following under the supervision of doctors. Expectedly, the prior knowledge about the basic infection control routine was very poor as was evident from the very low average pretest scores $(3.94 \pm 2.3$ out of 20$)$. However, the scores significantly improved (15.33 \pm 2.4 out of 20 ) after the didactic and practical sessions $(\mathrm{P}<0.05)$. The increase in the mean score was by 11.39, which was quite significant. Fitzpatrick et al. (18), in their study assessed the knowledge improvement regarding hand hygiene after demonstrating a train- 


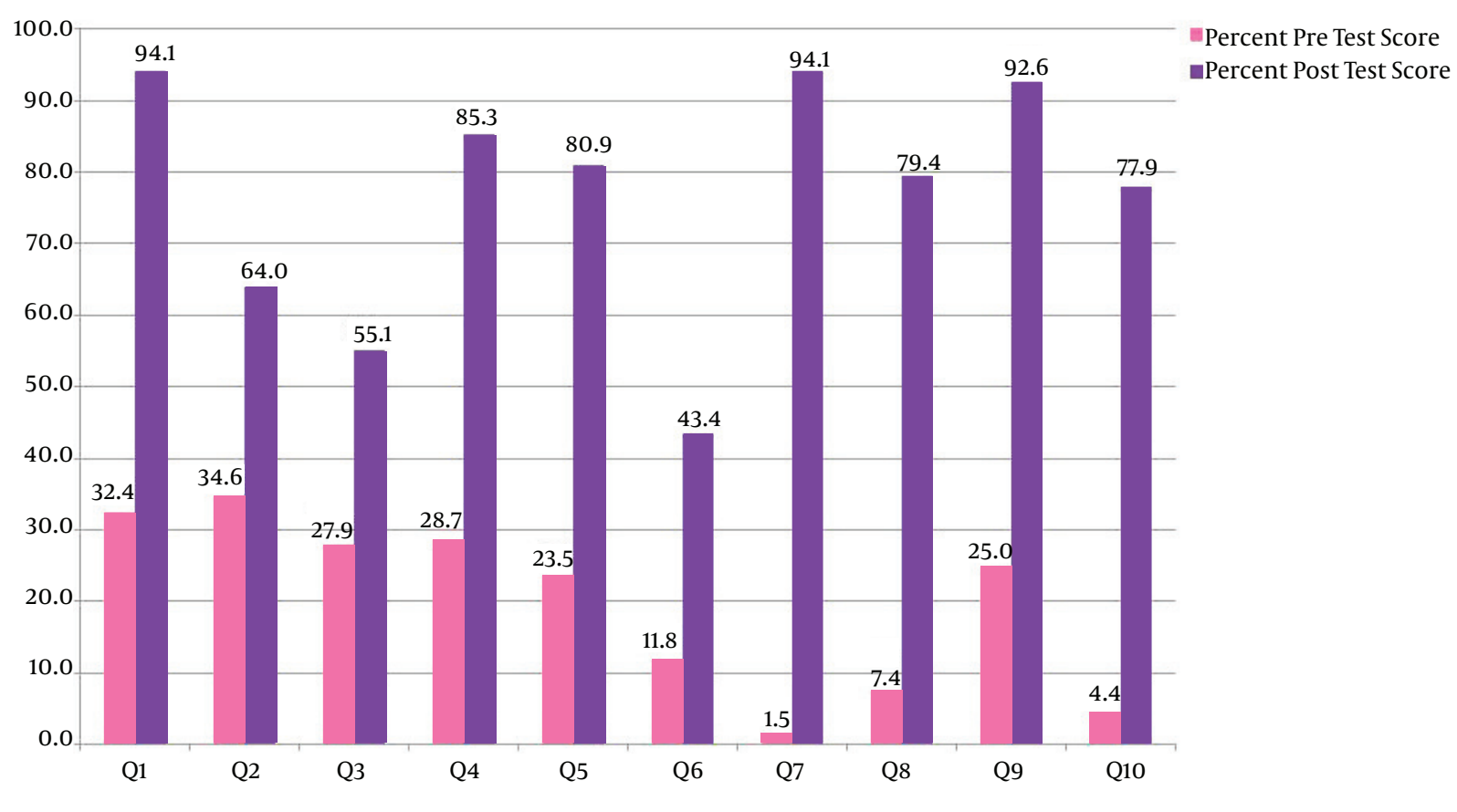

Figure 1. Pretest and posttest scores of the study participants

Table 3. Participants' Perception About the Educational Activity ${ }^{\mathrm{a}}$

\begin{tabular}{|c|c|c|c|c|c|}
\hline \multirow{2}{*}{ No. } & \multirow{2}{*}{ Parameter } & \multicolumn{2}{|c|}{ Participants Rating } & \multicolumn{2}{|c|}{ Mode } \\
\hline & & Before & After & Before & After \\
\hline 1. & Knowledge about the HAIs & $2.38 \pm 0.89$ & $4.06 \pm 0.80$ & 3 & 4 \\
\hline 2. & $\begin{array}{l}\text { Overall awareness about infection control } \\
\text { practices }\end{array}$ & $2.56 \pm 0.99$ & $4.03 \pm 0.72$ & 3 & 4 \\
\hline 3. & $\begin{array}{l}\text { Awareness about universal safety } \\
\text { precautions }\end{array}$ & $2.74 \pm 0.96$ & $4.18 \pm 0.63$ & 3 & 4 \\
\hline 4. & $\begin{array}{l}\text { Knowledge about ideal parameters for hand } \\
\text { washing }\end{array}$ & $2.62 \pm 0.89$ & $4.15 \pm 0.56$ & 3 & 4 \\
\hline 5. & $\begin{array}{l}\text { Knowledge about infection control in } \\
\text { operation theatres }\end{array}$ & $2.56 \pm 0.79$ & $4.21 \pm 0.48$ & 3 & 4 \\
\hline 6. & $\begin{array}{l}\text { Knowledge about housekeeping practices in } \\
\text { the hospital }\end{array}$ & $2.56 \pm 0.93$ & $4.32 \pm 0.64$ & 3 & 4 \\
\hline 7. & $\begin{array}{l}\text { Knowledge about sterilization and } \\
\text { disinfection of various items }\end{array}$ & $2.56 \pm 0.93$ & $4.33 \pm 0.65$ & 3 & 4 \\
\hline 8. & $\begin{array}{l}\text { Knowledge about occupational exposure } \\
\text { and post-exposure prophylaxis }\end{array}$ & $2.53 \pm 1.05$ & $4.09 \pm 0.67$ & 3 & 4 \\
\hline 9. & $\begin{array}{c}\text { Knowledge about segregation and disposal } \\
\text { of biomedical waste }\end{array}$ & $2.68 \pm 1.04$ & $4.38 \pm 0.60$ & 3 & 4 \\
\hline 10. & $\begin{array}{l}\text { Ability to implement infection control } \\
\text { practices at the workplace }\end{array}$ & $2.62 \pm 0.89$ & $4.24 \pm 0.55$ & 3 & 4 \\
\hline
\end{tabular}

${ }^{\mathrm{a}}$ Values are expressed as mean $\pm \mathrm{SD}$.

ing video to 244 participants including 88 nurses. They demonstrated an increase in the mean posttest score by 0.2499 among nurses and by 0.1704 and 0.1990 among medical students and physicians, respectively. In a study measuring the effect of a one day educational intervention on knowledge regarding the use of disinfectants by 


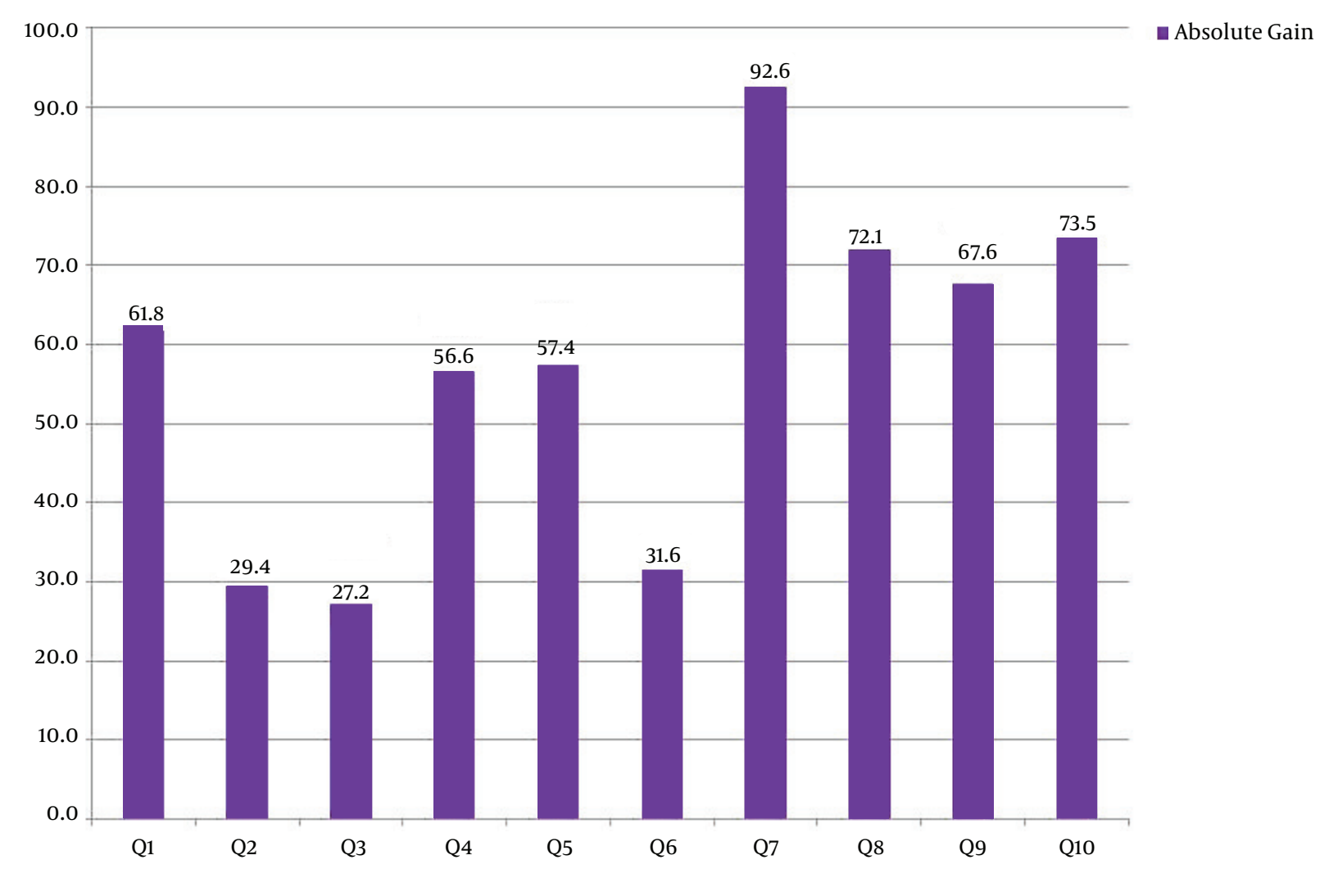

Figure 2. Absolute learning gain for the study participants

nursing staff demonstrated significant improvement in the posttest scores for items related to different aspects of disinfectant use such as categorization of commonly used medical and surgical devices, categorization of disinfectants as high, intermediate, and low level disinfectants and other aspects related to disinfectant use in hospital (19).

Item-wise analysis of the questionnaire showed that, pretest score for questions 7,8 , and 10 was considerably lower, which increased notably after the intervention indicating a remarkable learning gain through the intervention. These questions were based upon fumigation procedure, biomedical waste management, and management of accidental spillage of blood or body fluids.

Conversely, absolute learning gain of less than $50 \%$ was observed in questions 2, 3, and 6, refuting the usefulness of educational activity for these particular aspects. These three questions were based upon the knowledge about cleaning, disinfection, and sterilization practices used in the hospital for the environment and equipment considered the most vital area in infection control. Since nurses are the integral parts of this process, mandatory knowledge about the instruments and chemicals used in ster- ilization and disinfection is expected. However, surprisingly, participants showed limited prior knowledge about this important aspect, especially regarding the use of disinfectant solutions. Even after intervention, the expected level could not be achieved. Although unanticipated in the present study, similar kinds of unawareness were also observed in a study by Keah et al., (20) where $23.1 \%$ of HCWs did not know the temperature of sterilization while $72.4 \%$ did not have sufficient knowledge of the use of disinfectants with very little improvement in the average knowledge (from $44.4 \%$ to $57.3 \%$ ) after educating them. Somewhat similar results were obtained by Angellilo et al., (21) in the responses they obtained from 216 nurses of which, $10 \%$ did not believe that items should be rinsed in water after contact with glutaraldehyde and more than $25 \%$ thought that 10 minutes contact time provided sterilization. This reflects a poor knowledge or ignorance on the part of HCWs about this important aspect, which is actually a serious concern. It was felt that these aspects should be given more emphasize in the form of repeated practical exposure, compulsory posting of nursing staff for a few days in central sterile supply departments (CSSDs), contin- 
uous monitoring of the techniques by infection control team members and periodically auditing the use of disinfectants in the wards.

Questionnaire analysis also revealed an improved knowledge of the other important practices such as hand washing, standard precautions, safe disposal of biomedical waste, and spillage management. All these topics covered using practical sessions had added impact on increasing the level of understanding of the topic.

It is usually difficult to prove that a learning gain occurs as a result of educational intervention due to various factors as stated by Colt et al. (22). Therefore, many educators now use class average normalized gain and the related metrics to gauge a course's effectiveness since they are independent of study group's pretest level of knowledge $(22,23)$. Therefore, the current study was also based upon a one-day educational intervention toward cognitive gain assessment; the same parameters were used to evaluate the performance. The class-average normalized gain was categorized as follows: $0.1-0.29$ low gain, $0.3-0.69$ medium gain, and 0.7 -1.0 high gain. A class average normalized gain of more than 0.7 , as defined by the Hake criteria (24), indicates that educational intervention in form of a one-day CME and workshop was highly effective.

The perception of activity by the participants was noteworthy as evident by the increase in participants' rating score. Many of them were of the opinion that these kinds of activities should be regularly conducted for them in future as well.

Being sure of retention of the knowledge after the education is also equally important. As per Suchitra and Laxmi Devi (25), the knowledge, attitude, and practice (KAP) scores were definitely improved in the first post education assessment (after six months) but declined in the post education second assessment (after 12 months) and still further dropped in the third post-education assessment (after 24 months). Retention of knowledge after several weeks was a disappointing experience in some participant groups as stated by Wanger et al., (26) in their study giving a thrust on multiple and simultaneous strategies to improve compliance with infection control mandates. Hence, it is recommended that yearly or half yearly teaching and practical sessions should be organized to ensure better retention of knowledge and positive effect on infection control procedures.

A targeted educational intervention can have considerable effect on long-term reduction of HAIs. Safdar and Abad (27) in their review of 26 studies involving varied study populations of healthcare providers and using a number of different educational programs demonstrated statistically significant decrease in the infection rates after intervention in 21 studies, with risk ratios ranging 0 to 0.79 .
Cluster randomized trials using validated educational interventions and costing methods were the recommended ways to determine the independent effect of education on reduced HAIs as well as cost-savings.

On the contrary, a detailed review by Ward et al. (28), on the role of education to prevent and control infections reflected no clear and definite link between education and practice in the long-term, despite the fact that lack of knowledge and education was identified as a reason for poor practice by healthcare staff. The current study, regardless of demonstrating overall gain in knowledge, failed to assess the ultimate long-term benefit in terms of reduction in hospital acquired infections in each ward. It was supposedly the most difficult part to evaluate in any other case since improvement in clinical practice may not be solely attributable to knowledge gain by one day educational intervention. In practical settings, there are multiple variables, which can impact both on practice and outcomes including workload, skill mix, staff risk perception, time pressures and facilities available for staff to use (28). Further studies are needed to address why knowledge does not necessarily improve practice. Hence, it is recommended that further studies should be planned inclusive of these measures to assess sustained improvement in infection control practice by HCWs.

\subsection{Conclusion}

Educational intervention has a significant impact on improving the knowledge of nursing staff with respect to infection control practices. Educational interventions at periodic intervals should be encouraged to facilitate the knowledge of HCWs on best infection control practices, which help to decrease the healthcare associated infections.

\section{References}

1. WHO. Health Care-associated Infections Fact Sheet. 2016, [cited 2016 May 04]. Available from: http://www.who.int/gpsc/country_work/gpsc_ ccisc_fact_sheet_en.pdf.

2. Christopher S. Implementation of a Need Based Participatory Training Program on Hospital Infection Control: A Clinical Practice Improvement Project, Infection Control -Updates [internet]. 2012, [cited 24 March 2014]. Available from: http://www.intechopen.com/books/infectioncontrol-updates/infection-control-practiceimprovement.

3. WHO. Practical guidelines for infection control in health care facilities. WHO, SEARO regional publication; 2004. $41 \mathrm{p}$.

4. Larson E, Aiello AE. Systematic risk assessment methods for the infection control professional. Am J Infect Control. 2006;34(5):323-6. doi: 10.1016/j.ajic.2005.10.009. [PubMed: 16765214].

5. Kim LE, Evanoff BA, Parks RL, Jeffe DB, Mutha S, Haase C, et al. Compliance with Universal Precautions among emergency department personnel: Implications for prevention programs. American Journal of Infection Control.1999;27(5):453-5. doi: 10.1016/s0196-6553(99)70014-3. 
6. Gould D, Chamberlain A. The use of a ward-based educational teaching package to enhance nurses' compliance with infection control procedures. J Clin Nurs. 1997;6(1):55-67. [PubMed: 9052110].

7. Mikkelsen J, Reime MH, Harris AK. Nursing students' learning of managing cross-infections-scenario-based simulation training versus study groups. Nurse Educ Today. 2008;28(6):664-71. doi: 10.1016/j.nedt.2007.11.003. [PubMed: 18164104].

8. Cheng SM, Melanee EC, Rawson B. Infection prevention and control learning preferences of nurses sampled at a teaching hospital. Can J Infect Control. 2008;23(3):165-6.168-71. [PubMed:19024810].

9. Reime MH, Harris A, Aksnes J, Mikkelsen J. The most successful method in teaching nursing students infection control - Elearning or lecture? Nurse Educ Today. 2008;28(7):798-806. doi: 10.1016/j.nedt.2008.03.005. [PubMed:18442872].

10. Bryce E, Yassi A, Maultsaid D. E-learning of infection control: it's contagious. Canadian JInfect Cont. 2008;23(4):28-32.

11. Columbine AM, Wharrad HJ. Using computer technology to deliver an infection control update on hand hygiene. British Journal of Infection Control. 2016;8(3):14-9. doi: 10.1177/14690446070080030601.

12. Davis D, O'Brien MA, Freemantle N, Wolf FM, Mazmanian P, TaylorVaisey A. Impact of formal continuing medical education: do conferences, workshops, rounds, and other traditional continuing education activities change physician behavior or health care outcomes? JAMA. 1999;282(9):867-74. [PubMed: 10478694].

13. O'Brien MA, Rogers S, Jamtvedt G, Oxman AD, Odgaard-Jensen J, Kristoffersen DT, et al. Educational outreach visits: effects on professional practice and health care outcomes. Cochrane Database of Systematic Reviews. 2007. doi: 10.1002/14651858.CD000409.pub2.

14. Mani R, Rao R. Impact on Health care associated Infection rates by Continuous training of Nursing staff in our hospital. International Journal of Infection Control. 2012;8(2). doi:10.3396/ijic.v8i2.018.12.

15. Hassan AK, Moftah FM, Alaa El-Din SM, Bayomi SS. Assessment of an educational training program for nurses working in maternal and child health $(\mathrm{MCH})$ centers in Assiut city regarding infection control. Ass Uni Bull Environ Res. 2004;7(2):91-105.

16. Atalla HR, Aboalizm SE, Shaban HA. Effect of nursing guidelines compliance to infection control prevention among nursing student. IOSR J Nurs Health Sci. 2016;5(1):23-34.

17. Dogra S, Mahajan R, Jad B, Mahajan B. Educational interventions to improve knowledge and skills of interns towards prevention and control of hospital-associated infections. Int J Appl Basic Med Res. 2015;5(Suppl 1):S54-7. doi: 10.4103/2229-516X.162279. [PubMed: 26380213]. [PubMed Central: PMC4552068].

18. Fitzpatrick M, Everett-Thomas R, Nevo I, Shekhter I, Rosen LF, Schein- man SR, et al. A novel educational programme to improve knowledge regarding health care-associated infection and hand hygiene. Int J Nurs Pract. 2011;17(3):269-74. doi: 10.1111/j.1440-172X.2011.01934.X. [PubMed: 21605267].

19. Burute S, Murthy M, Ramanand S, Pore S, Karande V, Akat P. Immediate impact of an educational intervention on knowledge of use of disinfectants in nurses. International Journal of Basic \& Clinical Pharmacology. 2014;3(3):507. doi:10.5455/2319-2003.ijbcp20140618.

20. Keah KC, Jegathesan M, Tan SC, Chan SH, Che OM, Cheong YM, et al. An evaluation of knowledge and awareness of disinfection and sterilization among health care workers. Southeast Asian J Trop Med Public Health. 1995;26(1):51-6. [PubMed: 8525420].

21. Angelillo IF, Mazziotta A, Nicotera G. Nurses and hospital infection control: knowledge, attitudes and behaviour of Italian operating theatre staff. J Hosp Infect. 1999;42(2):105-12. doi: 10.1053/jhin.1998.0571. [PubMed: 10389059].

22. Colt HG, Davoudi M, Murgu S, Zamanian Rohani N. Measuring learning gain during a one-day introductory bronchoscopy course. Surg Endosc. 2011;25(1):207-16. doi: 10.1007/s00464-010-1161-4. [PubMed: 20585964]. [PubMed Central: PMC3003781].

23. Gaikwad N, Tankhiwale S. Interactive E-learning module in pharmacology: a pilot project at a rural medical college in India. Perspect Med Educ. 2014;3(1):15-30. doi: 10.1007/s40037-013-0081-0. [PubMed: 24072666]. [PubMed Central: PMC3890000].

24. Hake RR. Interactive-engagement versus traditional methods: A sixthousand-student survey of mechanics test data for introductory physics courses. American Journal of Physics. 1998;66(1):64-74. doi: 10.1119/1.18809.

25. Suchitra JB, Lakshmi Devi N. Impact of education on knowledge, attitudes and practices among various categories of health care workers on nosocomial infections. Indian Journal of Medical Microbiology. 2007;25(3):181. doi: 10.4103/0255-0857.34757.

26. P. Wagner D , J. Parker C , E. Mavis B , Smith MK. An interdisciplinary infection control education intervention: necessary but not sufficient. J Grad Med Educ. 2011;3(2):203-10. doi: 10.4300/JGME-D-1000120.1. [PubMed: 22655143]. [PubMed Central: PMC3184921].

27. Safdar N, Abad C. Educational interventions for prevention of healthcare-associated infection: a systematic review. Crit Care Med. 2008;36(3):933-40. doi: 10.1097/CCM.0B013E318165FAF3. [PubMed: 18431283].

28. Ward DJ. The role of education in the prevention and control of infection: a review of the literature. Nurse Educ Today. 2011;31(1):9-17. doi: 10.1016/j.nedt.2010.03.007. [PubMed: 20409621]. 